\title{
An Integrative analysis of brick-and-mortar fashion store shopping motives, activities and experience
}

\author{
Bing $X u^{1}$, Jianhui Chen ${ }^{1}$ \\ ${ }^{1}$ College of Fashion and Art Design, Donghua University, Shanghai, China
}

Keywords: Brick-And-Mortar Fashion Store; Shopping Motive; Shopping Activity; Shopping Duration; Repatronage.

\begin{abstract}
The paper aims to provide an integrative analysis of consumers' shopping motives, activities, and shopping duration and repatronage intention, centering on brick-and-mortar fashion store. Perceptual shopping experience of clothing purchase was newly considered in the research, which was relatively researched less by previous researchers. Relative perceptual factors were considered into the research and hypothesis model of all factors' relationship was given in this research. A structured questionnaire was generated and copies were distributed to consumers in three prosperous cities of China. Internal relations of each factor were examined according to feedbacks, and managerial implications were given to fashion retail managers at the end.
\end{abstract}

\section{Introduction}

Brick-and-mortar fashion store shopping is a basic and traditional shopping form, which is about the combination of consumer's visual, tactile and olfactory feeling together with stores' music, lighting and salespeople etc. According to Industry Standard (2000), purchasing clothes in brick-and-mortar store has still been gaining more prevalence among a large number of consumers, and people make $90 \%$ of their fashion purchases at brick-and-mortar stores, although the threats from catalog and internet outlets are being fierce. What reasons give rise to the persistence and prevalence of in-store shopping (Cox A.D. et al., 2005)? There could be certain irreplaceable reasons that spur consumers to shop in brick-and-mortar fashion stores although the convenience brought by online shopping is enormous. Taking this into consideration, prior researchers have conducted many surveys to explore the association between different influence factors in street fashion stores or shopping malls and consumer's shopping experience (e.g., Schielke et al., 2015; Kinley et al., 2010).

Most of the studies on brick-and-mortar store's fashion purchasing experience are centered on the influence of one or several aspects of consumers`shopping motives and shopping environment; however, the perceptual shopping experience, such as tactile sense, have not been fully investigated. Furthermore, the integrative studies between buying motives, activities and shopping environment, as well as shopping duration and repatronage intention are still insufficient. The research aims to give an integrative analysis of brick-and-mortar fashion store's shopping motives, activities and consumer's shopping experience.

\section{Research Design}

This study aims to develop a richer and deeper understanding of the integrative action of shopping motive, activity, and shopping environment on consumer's brick-and-mortar shopping experience, providing more meaningful findings regarding fashion stores. This study differs from prior researches by providing a more comprehensive and more in-depth quantitative research centered on fashion shopping experience. In order to build a clear outline for the research, consumer's shopping experience is divided into three phases, i.e. pre-purchase, purchasing, and post-purchase.

Shopping motive is considered as the main factor of pre-purchase stage. Based on literatures (e.g., Rajamma et al., 2007; Cox A.D. et al., 2005; Arnold and Reynolds, 2003; Lim, 2003), six elements 
are chosen as the most critical motives for in-store shopping experience, i.e. enjoyment, socializing, physical activity, risk reduction, immediate possession, and new trend.

Consumer's shopping activity and shopping environment are both have great influence on in-store shopping experience during purchase time (purchasing phase). According to literatures (e.g., Kinley et al, 2010; Jeong et al., 2008; Workman and Caldwell, 2007; Taylor and Cosenza, 2002; Lee, 2000), six factors are considered to research in fashion shopping activity; they are as follows: see the exact color, observe 3D look, touch the materials or fabric, feel the quality, wear them or trying them on, and bargaining. Likewise, several elements are selected for fashion shopping environment based on previous researches (e.g., Gueguen's, 2012; Fiore and Kim, 2007; Yuksel, 2004); they are music, lighting, temperature and scent, shop architecture, decoration, color scheme, and shop assistants.

In regards to post-purchase phase, research is designed to find the relationship between 'activities and environment' and consumer's 'shopping duration and repatronage intention'. Several other factors are added into this phase based on literatures (Fiore and Kim, 2007; Cox A.D. et al., 2005), which are checkout speed, crowdedness, on-sale products, and new products.

Research Hypotheses. Based on models built by prior researchers (Fiore and Kim, 2007; Wakefield and Baker, 1998), nine hypotheses were derived regarding the relationship between shopping motive, activity, and experience of fashion in-store shopping.

$\mathrm{H1}$ : There is a positive relationship between the brick-and-mortar fashion store shopping motive and shopping duration.

H2: There is a positive relationship between the brick-and-mortar fashion store shopping environment and shopping duration.

H3: There is a positive relationship between the brick-and-mortar fashion store shopping motive and shopping repatronage.

H4: There is a positive relationship between the brick-and-mortar fashion store shopping environment and shopping repatronage.

H5: There is a positive relationship between the brick-and-mortar fashion store shopping duration and shopping repatronage.

H6: There is a positive relationship between checkout speed and not crowded and shopping duration.

H7: There is a negative relationship between products' price and shopping duration.

H8: There is a positive relationship between checkout speed and not crowded and shopping repatronage.

H9: There is a positive relationship between products' price and shopping repatronage.

\section{Research Methodology}

Survey Instrument. Based on a comprehensive review of the relevant literatures (Kinley et al., 2010; Yuksel, 2003; Taylor and Cosenza, 2002), questionnaire was employed. The questionnaire included all the hypotheses elements. People were asked to score the importance of each factor by 1 to 5. 1 means the least importance and 5 means the most importance.

Sampling. 500 structured questionnaires were distributed from January 2017 to March 2017, to stores in ten bustling streets located in three prosperous cities in China, namely: four main streets in Shanghai, three main streets in Beijing, and three main streets in Nanjing. After eliminating incomplete questionnaires, 212 out of 500 were subjected to further analysis; the overall response rate was $42.4 \%$.

\section{Analysis and Findings}

Data was processed by SPSS data analysis software and results were shown in the form of tables.

Hypothesis Testing. In order to test the hypothesized associations, Pearson product-moment correlations was utilized. Figure 1 shows the relationships between the factors, as well as the goodness-of-fit indices for the model with regard to chi-square $\left(\chi^{2} / \mathrm{df}<3.00\right)$. The overall results of the regression analysis indicated that five out of the nine hypotheses have been fully supported; those 
are H2, H4, H6, H7, and H9. The strongest path coefficients were between the brick-and-mortar fashion store shopping environment and shopping duration, and between the brick-and-mortar fashion store shopping environment and shopping repatronage intention. Therefore, one can conclude, from the model, that brick-and-mortar fashion store's ambient, design, and shop assistants have great influence on consumer's shopping duration and repatronage intentions. Furthermore, the high correlations between in-store products' price and shopping duration, between in-store products' price and shopping repatronage intention, and between checkout speed and not crowded and shopping duration, suggest that products' price influence consumer's shopping duration and repatronage intentions strongly, as well as that store's condition has prominent influence on shopping duration.

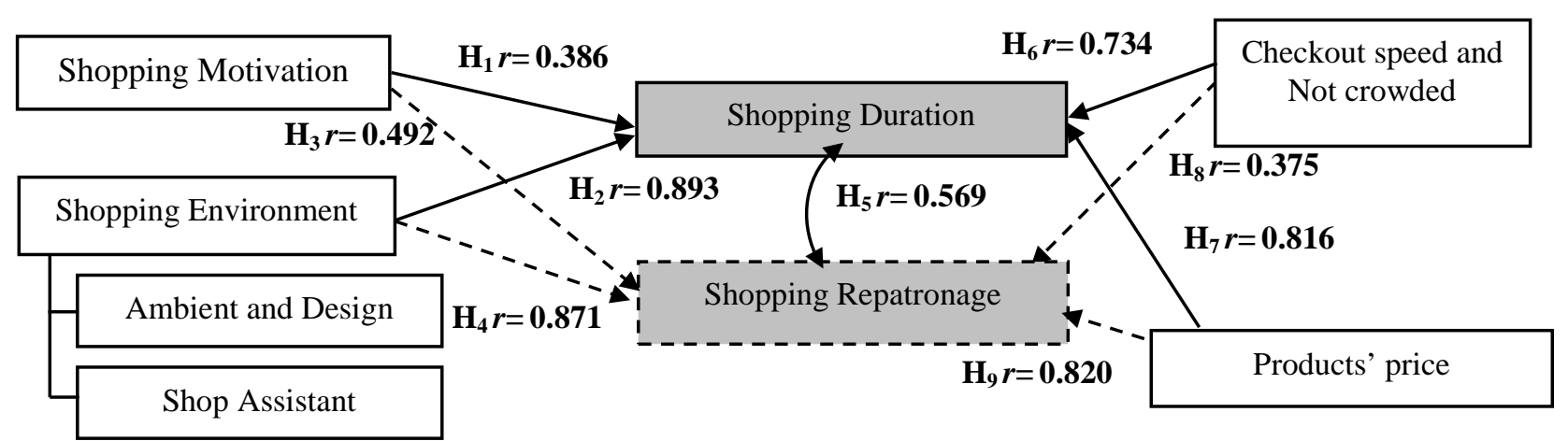

Figure 1. Factors that influence brick-and-mortar fashion store shopping experience. Note: $p<.005 ; \chi 2 / d f=2.378$.

Shopping Duration and Shopping Repatronage. Results of 'reasons for shopping duration' shows that 'pleasant ambience' was voted the most with a percentage of $69.3 \%$, which was followed by 'kind and helpful shop assistants' with a vote percentage of $66.5 \%$. Figures ranked in the middle are those of 'attractive store design' and 'fast checkout speed and not crowded'. Factors ranked relatively lower are 'many on-sale products' and 'often launch new products', with $42.9 \%$ and $39.2 \%$ vote rate respectively. Therefore, ambient, shop assistant, store design, and store's inner condition were the top 5 factors that gained more consideration when consumers consider staying in a fashion store longer.

Results of 'reasons for shopping repatronage intentions' shows that 'many on-sale products' and 'often launch new products' received the highest frequencies and vote rates $(127,59.9 \% ; 121,57.1 \%$ respectively). They are followed by 'pleasant ambience' and 'fast checkout speed and not crowded'. When compared, 'attractive store design' and 'kind and helpful shop assistants' got the relatively lower votes, which are $35.8 \%$ and $34.0 \%$ respectively. Therefore, it can be concluded that product price, new products, store condition, and ambient gained more consideration when consumers consider revisiting a fashion store.

\section{Conclusions and Discussion}

This paper has examined the influence of consumers' shopping motive, activity, and environment on their brick-and-mortar fashion store shopping duration and repatronage intention.

The motive section suggested that seeking for enjoyment and enhancing mood can be taken as the most important motive for consumers to shop in street fashion stores. This result supports that of McGuire (1974) who stated that shopping outside provides opportunities for people to relax whom are tend to seek ways to reduce tension in order to maintain inner equilibrium and return to a state of homeostasis. Also, Steenkamp and Baumgartner (1992) claimed that consumers could gain satisfaction and enjoyment by exploring fresh information or new merchandise around surroundings. Moreover, shopping provides a way to achieve self-gratifying, especially for those who view shopping as a 'pick-me-up' and 'lift' when they feel depressed (Babin et al., 1996). Reducing perceived shopping risks could be taken as another important motive for consumers. It supports that of Mitchell (1999, p.163) who stated that "consumers are more often motivated to avoid mistakes than to maximise utility in purchasing”. Socializing with friends or family is also considered to be of 
great importance, because shopping outside offers consumers opportunities to interact with reference groups and communicate with others having similar interests, and while interacting with others, consumers obtain satisfaction by seeking their own self-concepts, and gain self-identity by 'acting out' their roles which is considered by the community they are in (Tauber, 1972; McGuire, 1974).

For shopping activities in brick-and-mortar fashion store, the majority consumers thought that the most benefit they got from brick-and-mortar fashion store was that they can feel products' quality during shopping. It can be explained as that by feeling the quality, consumers are able to gain much relevant information about the products, and based on the information obtained, consumers will have more confidence of making the final purchasing decisions. Besides feeling the quality, consumers also believe that it is very important that brick-and-mortar stores allow them to touch products' materials, observe products' exact color, and try on these products. On one hand, consumers can obtain detailed information by touching the materials or fabric and seeing the exact color of products, which will give them more confidence to make final purchasing decisions (O'Cass, 2004). On the other hand, trying on the clothes is able to reduce consumers' perceive shopping risks which helps them to make right decisions (Lim, 2003; Taylor, 1974).

In terms of ambient, it can be concluded that pleasant scent, comfortable temperature, and adequate light can apparently give rise to consumers' positive emotion for a fashion store. When it comes to shop assistants, staff service quality and staff knowledge gained more attention by consumers. According to Kinley et al. (2000), consumers are willing to ask for opinions from a reference group during clothing selection, and shop assistants are considered to be the reference group for information or advice. One reason consumers tend to listen to reference group's advices is that they want to reduce the perceived risks of purchase (Taylor and Cosenza, 2002). Therefore, shop assistants' service quality about whether they can give useful advice and their knowledge for products' information play important roles on consumers. Besides these factors, staff appearance and whether they are helpful gains much consideration as well.

A fashion store's ambience, design, checkout speed, crowding condition, and shop assistants have significant influence on consumers' shopping duration. However, product price and product prevalence state contribute more to consumers' repatronage intentions. Mano and Elliott (1997) explained that consumers can feel pride, excitement and satisfaction by finding out discounts and paying a reduce price, therefore, a store often offering discounts can gain more attention by consumers to revisit; many consumers want to keep up with the latest trends, new fashion and available innovations, therefore, they tend to visit the store which can meet these demands (Arnold and Reynolds, 2003).

\section{References}

[1] Arnold, M.J. and Reynolds, K.E. (2003) Hedonic shopping motivation. Journal of Retailing 79: 77-95.

[2] Babin, B.J. and Darden, W.R. (1996) Good and bad shopping vibes: spending and patronage satisfaction. Journal of Business Research 35: 201-206.

[3] Cox, A.D., Cox, D. and Anderson R.D. (2005) Reassessing the pleasures of in-store shopping. Journal of Business Research 58: 250-259.

[4] Fiore, A.M. and Kim, J. (2007) An integrative framework capturing experiential and utilitarian shopping experience. International Journal of Retail \& Distribution Management 35(6): 421-442.

[5] Gueguen, N. (2012) The Sweet Smell of...Implicit Helping: Effects of Pleasant Ambient Fragrance on Spontaneous Help in Shopping Malls. The Journal of Social Psychology 152(4): 397-400.

[6] Industry Standard PM. (2000) Catalogers wise to the net. Industry Standard 2000 3(5): 196. 
[7] Jeong, K., Jang, S., Chae, J., Cho, G. and Salvendy, G. (2008) Use of decision support for clothing products on the web results in no difference in perception of tactile sensation than actually touching the material. Journal of Human-computer Interaction 24(8): 794-808.

[8] Kinley, T.R., Josiam, B.M. and Lockett, F. (2010) Shopping behavior and the involvement construct. Journal of Fashion Marketing and Management 14(4): 562-575.

[9] Lee, Y.D. (2000) Retail bargaining behaviour of American and Chinese customers. European Journal of Marketing 34(1/2): 190-206.

[10]Lim, N. (2003) Consumers perceived risk: Sources versus consequences. Electronic Commerce Research and Applications 2: 216-228.

[11] Mano, H. and Elliott, M. (1997) Smart shopping: the origins and consequences of price savings. In: MacInnis, D. and Brucks, M., editors. Advances in consumer research, (24), Provo (UT): Association for Consumer Research, pp. 504-510.

[12] McGuire, W. (1974) Psychological motives and communication gratification. In: Blumer, J.F. and Katz, editors., The uses of mass communication: Current perspectives on gratification research. Beverly Hills: Sage, pp. 106-167.

[13] Mitchell, V. (1999) Consumer perceived risk: conceptualisations and models. Eur. J. Market 33 (1/2): 163-195.

Rajamma, R.K., Paswan A.K. and Ganesh G. (2007) Emerald Article: Services purchased at brick and mortar versus online stores, and shopping motivation. Journal of Services Marketing 21(3): 200-212.

[14] Steenkamp J.B. and Baumgartner H. (1992) The role of optimum stimulation level in exploratory consumer behavior. J Consum Res 19(12): 434- 448.

[15] Tauber, E. M. (1972) Why do people shop? Journal of Marketing 36(10): 46-49.

[16] Taylor, S.L. and Cosenza, R.M. (2002) Profiling later aged female teens: mall shopping behavior and clothing choice. Journal of Consumer Marketing 19(5): 393-408.

[17]Wakefield, K.L. and Baker, J. (1998) Excitement at the Mall: Determinants and Effects on Shopping Response. Journal of Retailing 74(4): 515-539.

[18]Workman, J.E. and Caldwell, L.F. (2007) Centrality of visual product aesthetics, tactile and uniqueness needs of fashion consumers. International Journal of Consumer Studies 31: 589-596.

[19] Yuksel, A. (2004) Shopping experience evaluation: a case of domestic and international visitors. Tourism Management 25: 751-759. 